\title{
Regional variations in the sexually transmitted disease clinic service in England and Wales
}

\author{
G M HOUGHTON, M W ADLER, AND E M BELSEY \\ From the Academic Department of Genitourinary Medicine, Middlesex Hospital Medical School, London
}

\begin{abstract}
SUMMARY The provision of the sexually transmitted disease clinic service in the regional health authorities of England and Wales has been compared by relating the opening hours of clinics to the size of the population served. Relatively low levels of service were provided in the West Midlands and South-west Thames regions and high levels in the North-east and North-west Thames regions. When the service in the Greater London area health authorities was examined in relation to both resident and day-time populations, provision was relatively high in both instances, particularly in certain central London areas. Valid conclusions, however, about the equality of the service in different areas can only be drawn if the needs of the population for that service are known.
\end{abstract}

\section{Introduction}

In 1976-77 a survey of sexually transmitted disease (STD) clinics in England and Wales was carried out to determine the hours open, and the facilities, diagnostic and treatment methods, and notification procedures used. The methodology and findings of this study have been reported. ${ }^{1-7}$ The survey established that the hours STD clinics were open varied greatly in England and Wales (from one to $491 / 2$ hours a week) and that $53 \%$ of the clinics were open for 10 hours or less a week.

In this study the geographical distribution of the STD clinic service in England and Wales was investigated by examining the accessibility of clinics to the population they serve. This was carried out by relating the number of hours clinics were open to the population in particular areas of England and Wales.

\section{Methods}

CLINICS

At the time of the original survey there were 103 consultants in charge of 189 clinics, of whom 95 (representing 175 clinics) agreed to take part in the survey. Information obtained in the former study on the hours that STD clinics were open is used in this paper. Since that study was completed the number of

Address for reprints: Professor M W Adler, Academic Department of Genitourinary Medicine, James Pringle House, Middlesex Hospital, London WIN 8AA

Accepted for publication 29 April 1980 clinics presently open has changed; three new clinics have opened and two have closed, bringing the total number of STD clinics in England and Wales to 190. For the clinics not included in the original study hours open were taken from information published in the Department of Health and Social Security's (DHSS) list of STD clinics (as amended in August 1978). ${ }^{8}$

\section{POPULATION}

The regional health authority (RHA), of which there are 14 in England and Wales, was taken as the basic geographical unit for analysis. Division of England and Wales into smaller units would have provided too many areas for meaningful comparisons and larger units would have tended to conceal any differences in the provision of the STD clinic service which may exist. The data on the resident population were taken from the DHSS revised population figures for health districts (based on the 1971 census). For each regional health authority, the populations of all its constituent health districts were summated to produce a final resident population total.

DATA ANALYSIS

Data used in the calculation of day-time populations for areas in the south-east of England were taken from census data for 1971 for England and Wales. ${ }^{9}$ The number of people moving into and out of each county and London borough in south-east England for working purposes each day was established by calculation. A cut-off point of 100 persons was used, below which movement was disregarded. In this way 
the increase or decrease of population during the day for each area was found. The resident population of each area was then adjusted to produce final daytime population totals. These figures for each county and London borough were combined to establish the total increase or decrease in population during the day for the four Thames RHAs and for area health authorities (AHAs) in south-east England; the resident populations of the RHAs and AHAs were then adjusted accordingly.

To provide a single measure for comparison of the STD clinic service between regions an index relating weekly clinic opening hours to population has been calculated for each RHA. The average, represented by an index of 100 , was taken to be the total number of hours all clinics in England and Wales were open per week divided by the total population of England and Wales. The index for each region was found by dividing its own ratio of weekly clinic hours to population by the national average. Similar indices were calculated by relating total hours open after $5 \mathrm{pm}$, hours open on Saturday, and the number of clinics in each region to its population. Indices relating weekly clinic hours to resident population and to day-time population for counties in south-east England and London boroughs were produced in the same way.

\section{Results}

\section{WEST MIDLANDS}

The largest region in terms of population was the West Midlands, having $10 \cdot 5 \%$ of the population of England and Wales (table I). It had the lowest index of number of clinics $(70 \cdot 2)$ and the second lowest index of weekly clinic hours $(64 \cdot 8)$. Nine of the region's 14 clinics were open for 10 hours or less each week, although two clinics were open full-time (40-50 hours a week) (table II). It had a relatively low provision of STD clinic service after $5 \mathrm{pm}$, having the lowest index of $62 \cdot 6$, and on Saturday there was no clinic open anywhere in the region (table III). However, although from these figures the region seems to have an extremely low provision of STD clinic service, the West Midlands Metropolitan County, which covers the Birmingham conurbation, accounts for over half the population of the region and, although only $35 \%$ of the clinics are located here, they contribute $56 \%$ of the weekly clinic hours of the region. This means that intraregionally, the distribution of clinic hours and population is more evenly balanced than would at first appear.

TABLE II Clinic opening times by regional health authority

\begin{tabular}{|c|c|c|c|c|c|c|}
\hline \multirow[b]{2}{*}{ Regions } & \multirow{2}{*}{$\begin{array}{l}\text { Total No } \\
\text { of clinics }\end{array}$} & \multicolumn{5}{|c|}{ No of clinics open for (hours/week): } \\
\hline & & $\leqslant 10$ & $11-20$ & $21-30$ & $31-40$ & $40-50$ \\
\hline Northern & 13 & 7 & 4 & 1 & 1 & $\mathbf{0}$ \\
\hline Trent & 15 & 8 & 3 & 2 & 2 & $\mathbf{0}$ \\
\hline Yorkshire & 14 & 5 & 5 & 1 & 3 & $\mathbf{0}$ \\
\hline E Anglia & 8 & 4 & 3 & 1 & $\mathbf{0}$ & $\mathbf{0}$ \\
\hline N-W Thames & 13 & 2 & 5 & 0 & 3 & 3 \\
\hline N-E Thames & 16 & 4 & 2 & 5 & 3 & 2 \\
\hline S-E Thames & 17 & 9 & 2 & $\mathbf{0}$ & 4 & 2 \\
\hline S-W Thames & 10 & 6 & 3 & 1 & $\mathbf{0}$ & $\mathbf{0}$ \\
\hline Wessex & 11 & 8 & $\mathbf{0}$ & 2 & 0 & 1 \\
\hline Oxford & 7 & 4 & 2 & 1 & 0 & 0 \\
\hline S Western & 16 & 14 & $\overline{\mathbf{I}}$ & $\mathbf{0}$ & 1 & $\mathbf{0}$ \\
\hline W Midlands & 14 & 9 & 2 & 1 & $\mathbf{0}$ & 2 \\
\hline Mersey & 9 & 5 & 2 & 1 & 1 & $\mathbf{0}$ \\
\hline N Western & 15 & 12 & 1 & 1 & 1 & $\mathbf{0}$ \\
\hline Wales & 12 & 8 & 2 & 1 & 1 & $\mathbf{0}$ \\
\hline Total & 190 & 105 & 37 & 18 & 20 & 10 \\
\hline
\end{tabular}

SOUTH-WESTERN REGION

The South-western region had the highest index for number of clinics $(\mathbf{1 3 8} \cdot 3)$ but the lowest for weekly

TABLE I Resident population and indices of number of STD clinics and number of hours of STD clinic service by regional health authority

\begin{tabular}{|c|c|c|c|c|}
\hline \multirow[b]{2}{*}{ Regions } & \multicolumn{2}{|c|}{ Resident population } & \multirow{2}{*}{$\begin{array}{l}\text { Index of No } \\
\text { of clinics/population }\end{array}$} & \multirow{2}{*}{$\begin{array}{l}\text { Index of No of hours } \\
\text { open weekly/population }\end{array}$} \\
\hline & No $(\times 1000)$ & $\%$ & & \\
\hline Northern & $3121 \cdot 6$ & $6 \cdot 3$ & $107 \cdot 8$ & $85 \cdot 6$ \\
\hline Trent & $4515 \cdot 6$ & $9 \cdot 2$ & $85 \cdot 9$ & $89 \cdot 1$ \\
\hline Yorkshire & $3577 \cdot 9$ & $7 \cdot 3$ & $101 \cdot 3$ & $111 \cdot 4$ \\
\hline East Anglia & $1802 \cdot 7$ & $3 \cdot 7$ & $114 \cdot 9$ & $83 \cdot 1$ \\
\hline N-W Thames & $3438 \cdot 3$ & $7 \cdot 0$ & 97.9 & $168 \cdot 2$ \\
\hline S-E Thames & $3579 \cdot 8$ & $7 \cdot 3$ & $122 \cdot 9$ & 159.9 \\
\hline S-W Thames & $2983 \cdot 2$ & $6 \cdot 1$ & $86 \cdot 8$ & $66 \cdot 5$ \\
\hline Wessex & $2693 \cdot 1$ & $5 \cdot 5$ & $105 \cdot 7$ & $97 \cdot 7$ \\
\hline Oxford & $2217 \cdot 0$ & $4 \cdot 5$ & $81 \cdot 7$ & $69 \cdot 2$ \\
\hline S Western & $2993 \cdot 7$ & $6 \cdot 1$ & $138 \cdot 3$ & $58 \cdot 6$ \\
\hline West Midlands & $5164 \cdot 5$ & $10 \cdot 5$ & $70 \cdot 2$ & $64 \cdot 8$ \\
\hline Mersey & $2490 \cdot 7$ & $5 \cdot 0$ & $93 \cdot 5$ & $75 \cdot 0$ \\
\hline N Western & $4090 \cdot 9$ & $8 \cdot 3$ & $94 \cdot 9$ & $69 \cdot 8$ \\
\hline Wales & $2766 \cdot 1$ & $5 \cdot 6$ & $112 \cdot 3$ & $86 \cdot 0$ \\
\hline
\end{tabular}


TABLE III No of STD clinics open after 5 pm and on Saturday by regional health authority

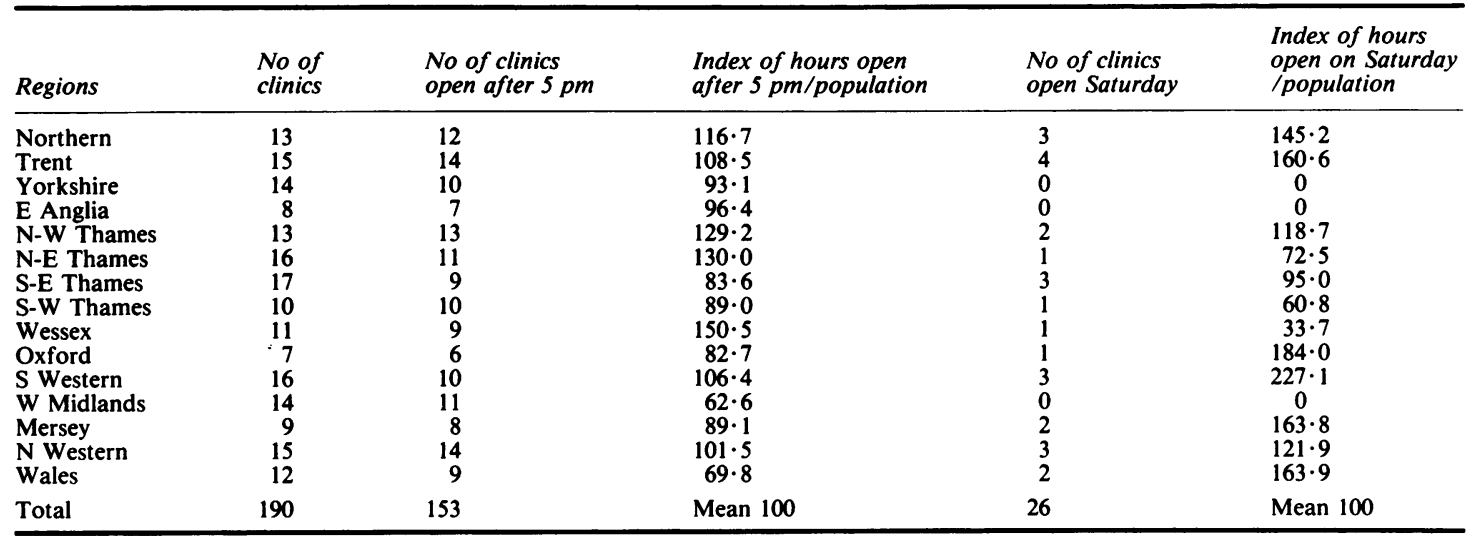

clinic hours $(58 \cdot 6$; table I). Nearly all the region's clinics (14 out of 16) were open for 10 hours or less per week (table II). In contrast to the low weekly hours of clinic service, the region had a near average provision of opening hours after $5 \mathrm{pm}(106 \cdot 4)$ and an extremely high index for hours on Saturday $(227 \cdot 1)$ (table III). The variation in indices for the region demonstrates the large number of clinics which open for short periods only each week (11 clinics in the region were open for less than five hours a week). The high index for Saturday hours was accounted for by only two clinics, Bristol and Plymouth.

\section{WA LES}

In some respects, Wales RHA has a pattern of STD clinic provision similar to that of the South-western region. Wales too had an above average number of clinics relative to population $(112 \cdot 3)$ but low weekly clinic hours $(86 \cdot 0)$ (table I). It also had a fairly high proportion of clinics open for 10 hours or less per week (eight out of 12; table II) and an above-average service on Saturday $(163.9)$ (table III). On the other hand, Wales had a low provision of evening clinic service (69.8; table III). This low level of clinic service was, however, not uniform over the region. Of the 12 Welsh clinics the largest five accounting for $80 \%$ of Wales's clinic hours were clustered in a small area in the extreme south, which holds $60 \%$ of Wales's population. This concentration of provision results in the rest of Wales having an extremely low level of clinic service.

\section{OTHER AREAS}

From tables I-III, the low measures of weekly clinic service in Oxford, North-western, and Mersey regions and also the lack of a Saturday service in Yorkshire and East Anglia as well as that in the West Midlands region can be seen.
SOUTH-EAST AND GREATER LONDON

Three of the four Thames regional health authorities had a well above-average STD clinic service in most respects.

\section{$N-W$ Thames region}

North-west Thames RHA had a near-average number of clinics relative to population $(97 \cdot 9)$ but had the second highest index of weekly clinic hours $(168 \cdot 2$; table I). The region had fewest small clinics (two out of 13) and one of the largest number of clinics open full-time (three out of 13; table II). Every clinic in the region was open for some time after $5 \mathrm{pm}$, and Saturday opening hours were also above average $(118 \cdot 7$; table III).

\section{$N-E$ Thames region}

The neighbouring region of North-east Thames had an above-average number of clinics for its population $(110.5)$ and the highest index for weekly clinic hours (190.6; table I). Only four of its 16 clinics were open for 10 hours or less (table II). The region's index of 130.0 for hours open after $5 \mathrm{pm}$ was the second highest, but in the provision of Saturday hours it was below average $(72 \cdot 5$; table III).

\section{$S$-E Thames region}

South-east Thames region had indices of 122.9 and 159.9 for clinic numbers and weekly opening hours respectively (table $\mathrm{I})$. The region had an aboveaverage number of small clinics (nine out of 17) but two of its clinics were open full-time (table II). Indices for hours open after $5 \mathrm{pm}$ and on Saturday were below-average, being 83.6 and $95 \cdot 0$ respectively (table III). 


\section{$S$ - $W$ Thames region}

In contrast, South-west Thames had the lowest index $(66 \cdot 5)$ of all the regions for weekly clinic hours and a low index of clinic numbers $(86 \cdot 8$; table I). The region had an above-average number of small clinics (six out of 10), and no clinic was open for more than 30 hours per week (table II). All clinics in the region were open at some time after $5 \mathrm{pm}$ but for such a short time that the index for hours open after $5 \mathrm{pm}$ was below average $(89 \cdot 0)$ as was the index for Saturday hours of $60 \cdot 8$ (table III).

Together the Thames regions accounted for $28 \%$ of England's and Wales's resident populations (table IV). They had a near-average provision of clinics $(105 \cdot 4)$ and high weekly clinic hours $(150 \cdot 0)$. If the Greater London parts of the regions are examined separately, Greater London as a whole, comprising $14.5 \%$ of the resident population of England and Wales, had a near-average index of clinic numbers $(98 \cdot 0)$ but a very high index of weekly clinic hours $(210 \cdot 9)$. It should be noted, however, that while the North-west, North-east, and South-east Thames parts of Greater London had an extremely high provision of clinic hours $(211 \cdot 8,249 \cdot 0$, and $250 \cdot 7$ respectively), South-west Thames had an index below the national average $(89 \cdot 2)$. The remaining areas of the four regions outside Greater London had an index of clinic numbers of 113.5 but an index of clinic hours below average $(84 \cdot 5)$. The differences between Greater London and the remaining areas of the Thames regions in terms of the number of hours clinics were open after $5 \mathrm{pm}$ and on Saturday were even more marked. Therefore, the excesses in clinic hours, which are demonstrated in figures for the individual Thames regions, were accounted for solely by Greater London.
These results were related to resident populations of the individual areas. However, if it is assumed that patients are as likely to attend clinics near their place of work as near their place of residence, examination of the STD clinic service in relation to day-time population may therefore modify the above results. Similarly, when considering the population of Greater London, the large number of tourists, especially in central London, who may attend STD clinics should be taken into account. For example, in 1978 there were $8 \cdot 5$ million visits to London by overseas visitors and 12.6 million by British visitors. Unfortunately, it is beyond the scope of this paper to consider this factor, which may also modify results reached in relation to resident population.

Day-time populations were calculated as described earlier and the data for the Thames regions are shown in table IV. When figures for resident and day-time populations in Greater London are compared, the latter increases by $0.6 \%(14.5 \%$ to $15 \cdot 1 \%$ ). Therefore, examination of day-time population does not alter the conclusion that Greater London is extremely well provided with STD clinic services. However, the small increase in Greater London's day-time population suggests that using such a large geographical unit tends to minimise differences in population totals which may be apparent if smaller units are used. To reach valid conclusions it is necessary to examine area health authorities.

\section{AREA HEALTH AUTHORITIES}

When daily population movements in the South-east are compared, the most prominent commuter counties (as may be expected) are Surrey, Essex, Kent, and Hertfordshire, losing approximately

TABLE IV Precentage of resident population, day-time population, and index of clinic numbers and hours in the four Thames regional health authorities

\begin{tabular}{|c|c|c|c|c|c|c|}
\hline Area & $\begin{array}{l}\text { Resident } \\
\text { population } \\
\%\end{array}$ & $\begin{array}{l}\text { Day-time } \\
\text { population } \\
\%\end{array}$ & $\begin{array}{l}\text { Index of } \\
\text { No of clinics/ } \\
\text { resident } \\
\text { population }\end{array}$ & $\begin{array}{l}\text { Index of } \\
\text { hours weekly/ } \\
\text { resident } \\
\text { population }\end{array}$ & $\begin{array}{l}\text { Index of } \\
\text { hours after } \\
5 \text { pm/resident } \\
\text { population }\end{array}$ & $\begin{array}{l}\text { Index of } \\
\text { hours on } \\
\text { Saturday/ } \\
\text { resident } \\
\text { population }\end{array}$ \\
\hline $\begin{array}{l}\text { North-west Thames } \\
\text { North-east Thames } \\
\text { South-east Thames } \\
\text { South-west Thames } \\
\text { Total all Thames regions }\end{array}$ & $\begin{array}{r}7 \cdot 0 \\
7 \cdot 6 \\
7 \cdot 3 \\
6 \cdot 1 \\
28 \cdot 0\end{array}$ & $\begin{array}{r}7 \cdot 6 \\
8 \cdot 0 \\
6 \cdot 8 \\
5 \cdot 6 \\
28 \cdot 0\end{array}$ & $\begin{array}{r}97 \cdot 9 \\
110 \cdot 5 \\
122 \cdot 9 \\
86 \cdot 8 \\
105 \cdot 4\end{array}$ & $\begin{array}{r}168 \cdot 2 \\
190 \cdot 6 \\
159 \cdot 9 \\
66 \cdot 5 \\
150 \cdot 0\end{array}$ & $\begin{array}{r}129 \cdot 2 \\
130 \cdot 0 \\
83 \cdot 6 \\
89 \cdot 0 \\
108 \cdot 8\end{array}$ & $\begin{array}{r}118 \cdot 7 \\
72 \cdot 5 \\
95 \cdot 0 \\
60 \cdot 8 \\
87 \cdot 0\end{array}$ \\
\hline $\begin{array}{l}\text { N-W Thames (Greater London) } \\
\text { N-E Thames (Greater London) } \\
\text { S-E Thames (Greater London) } \\
\text { S-W Thames (Greater London) } \\
\text { Total (Greater London) }\end{array}$ & $\begin{array}{r}4 \cdot 3 \\
4 \cdot 7 \\
3 \cdot 0 \\
2 \cdot 5 \\
14 \cdot 5\end{array}$ & $\begin{array}{r}5 \cdot 0 \\
5 \cdot 3 \\
2 \cdot 6 \\
2 \cdot 2 \\
15 \cdot 1\end{array}$ & $\begin{array}{r}98 \cdot 2 \\
111 \cdot 5 \\
87 \cdot 7 \\
84 \cdot 4 \\
98 \cdot 0\end{array}$ & $\begin{array}{r}211 \cdot 8 \\
249 \cdot 0 \\
250 \cdot 7 \\
89 \cdot 2 \\
210 \cdot 9\end{array}$ & $\begin{array}{l}165 \cdot 9 \\
193 \cdot 3 \\
150 \cdot 4 \\
106 \cdot 2 \\
161 \cdot 3\end{array}$ & $\begin{array}{l}192 \cdot 5 \\
116 \cdot 6 \\
122 \cdot 2 \\
101 \cdot 5 \\
145 \cdot 5\end{array}$ \\
\hline $\begin{array}{l}\text { N-W Thames (Hertfordshire \& Bedfordshire) } \\
\text { N-E Thames (Essex) } \\
\text { S-E Thames (Kent \& East Sussex) } \\
\text { S-W Thames (Surrey \& West Sussex) } \\
\text { Total (counties) }\end{array}$ & $\begin{array}{r}2 \cdot 7 \\
2 \cdot 9 \\
4 \cdot 3 \\
3 \cdot 6 \\
13 \cdot 5\end{array}$ & $\begin{array}{r}2 \cdot 6 \\
2 \cdot 7 \\
4 \cdot 2 \\
3 \cdot 4 \\
12 \cdot 9\end{array}$ & $\begin{array}{r}97 \cdot 4 \\
108 \cdot 8 \\
147 \cdot 7 \\
88 \cdot 5 \\
113 \cdot 5\end{array}$ & $\begin{array}{r}101 \cdot 0 \\
95 \cdot 6 \\
96 \cdot 1 \\
50 \cdot 6 \\
84 \cdot 5\end{array}$ & $\begin{array}{r}70 \cdot 8 \\
27 \cdot 0 \\
100 \cdot 4 \\
77 \cdot 0 \\
52 \cdot 2\end{array}$ & $\begin{array}{c}0 \\
0 \\
75 \cdot 1 \\
0 \\
23 \cdot 9\end{array}$ \\
\hline
\end{tabular}


$90000,83000,46000$, and 32000 people respectively during the day. Most of the Greater London health areas also experience a decrease in population during the day. Areas in which a population gain occurs are Kensington, Chelsea, and Westminster area, gaining 441500 , the City and East London area, gaining 356 500, and Camden and Islington area, gaining 148500 . Hillingdon area and Hammersmith, Ealing, and Hounslow area also gain 16000 and 900 people respectively.

If the smaller geographical unit of the AHA is considered, the variation in indices of weekly clinic hours between AHAs becomes immediately apparent (table V) for resident and, to a lesser extent, day-time populations. Within Greater London four AHAs had no STD clinic service (shown by indices of zero) while, on the other hand, four AHAs had extremely high indices: Kensington, Chelsea, and Westminster; Camden and Islington; City and East London; and Lambeth, Southwark, and Lewisham. When indices relating to resident and day-time population for each Greater London health area are compared the change is often substantial (table V). In Kensington, Chelsea, and Westminster the excess in weekly clinic hours in relation to resident population (shown by an index of $725 \cdot 6$ ) is considerably reduced (to $344 \cdot 5$ ) when the higher day-time population is taken as the denominator. Similarly, for the City and East
London area and for Camden and Islington area the high indices in relation to resident population also decrease (from 442.6 to 274.0 and from 524.8 to 390.3 respectively) when clinic hours are related to day-time population. However, the level of STD clinic service in these areas was still much above average.

Conversely, in other areas the excess in weekly clinic hours in relation to resident population is actually increased when their lower day-time population is taken as the denominator. The increase is most substantial in Lambeth, Southwark, and Lewisham, where the excess in provision of clinic service for the resident population (shown by an index of 392.9 ) is even greater for the day-time population $(428 \cdot 8)$. This is due to a decrease in the population of the area during the day.

The indices for day-time population for AHAs outside Greater London were little different from their corresponding indices for resident population. West Sussex, Hertfordshire, Surrey, and Berkshire had very low levels of clinic service even after allowance has been made for the decrease in population during the day.

\section{Discussion}

In terms of England and Wales as a whole, certain

TABLE v Weekly clinic hours in South-east England

\begin{tabular}{|c|c|c|}
\hline Area health authorities & $\begin{array}{l}\text { Index of weekly hours/ } \\
\text { resident population }\end{array}$ & $\begin{array}{l}\text { Index of weekly hours } \\
\text { day-time population }\end{array}$ \\
\hline \multicolumn{3}{|l|}{ Greater London } \\
\hline Brent and Harrow & $70 \cdot 6$ & $80 \cdot 9$ \\
\hline Barnet & 0 & 0 \\
\hline Hillingdon & $125 \cdot 4$ & $117 \cdot 1$ \\
\hline Hammersmith, Ealing, and Hounslow & $148 \cdot 1$ & $147 \cdot 9$ \\
\hline Kensington, Chelsea, and Westminster & $725 \cdot 6$ & $344 \cdot 5$ \\
\hline Redbridge and Waltham Forest & 0 & 0 \\
\hline Barking and Havering & $121 \cdot 4$ & $136 \cdot 3$ \\
\hline City and East London & $442 \cdot 6$ & $274 \cdot 0$ \\
\hline Camden and Islington & $524 \cdot 8$ & $390 \cdot 3$ \\
\hline Greenwich and Bexley & $172 \cdot 8$ & $201 \cdot 1$ \\
\hline Bromley & 0 & 0 \\
\hline Croydon & $125 \cdot 4$ & $132 \cdot 2$ \\
\hline Sutton, Merton, and Wandsworth & $104 \cdot 1$ & $117 \cdot 7$ \\
\hline Kingston and Richmond & 0 & 0 \\
\hline \multicolumn{3}{|l|}{ S-E England } \\
\hline Kent & $104 \cdot 7$ & $108 \cdot 1$ \\
\hline East Sussex & $76 \cdot 9$ & $78 \cdot 0$ \\
\hline West Sussex & $45 \cdot 3$ & $46 \cdot 1$ \\
\hline Hampshire & $120 \cdot 8$ & $120 \cdot 9$ \\
\hline Surrey & $53 \cdot 5$ & $58 \cdot 1$ \\
\hline Berkshire & $57 \cdot 4$ & $58 \cdot 6$ \\
\hline Oxford & $110 \cdot 8$ & $111 \cdot 2$ \\
\hline Buckinghamshire & $69 \cdot 4$ & $72 \cdot 2$ \\
\hline Bedfordshire & $194 \cdot 2$ & $195 \cdot 1$ \\
\hline Hertfordshire & $43 \cdot 1$ & $44 \cdot 9$ \\
\hline Essex & $95 \cdot 6$ & $101 \cdot 5$ \\
\hline Mean (England and Wales) & 100 & 100 \\
\hline
\end{tabular}


regions are notable for their relatively low provision of STD clinic services. West Midlands Region and South-west Thames Region had consistently low indices. Mersey, Oxford, and East Anglia also had below average provision. The highest levels of provision were in North-east Thames and North-west Thames regions. Variation in regional STD clinic services is therefore quite marked.

Greater London has approximately $15 \%$ of the country's population and $30 \%$ of its STD clinic hours. However, it is evident that only a few areas are responsible for this high level of provision, namely Kensington, Chelsea, and Westminster, City and East London, and Camden and Islington. In relation to the resident population the number of hours clinics in these areas are open seems excessive. However, the large number of people commuting into these same areas means that the excess in clinic hours is reduced when related to the day-time population. If it had been possible also to take into account the large numbers of tourists in these areas, a further reduction in indices might have been apparent. Nevertheless, clinic service in relation to day-time population was three times the national average. In one area, Lambeth, Southwark, and Lewisham, the level of STD clinic provision was four times the national average.

The evidence presented in this paper tends to suggest that Greater London is over-provided (particularly in specific areas) with an STD clinic service compared with the rest of England and Wales. In 1978 , however, $42 \%$ of all new cases seen in clinics in England and Wales were in Greater London, which suggests that Greater London is by no means overprovided.

However, this is a measure of the use of the STD clinic service. It only reflects a demand for treatment, which is actually being met, and does not necessarily indicate that there is a greater need for STD clinic facilities in Greater London. Demand in Greater London may be higher than elsewhere in England and Wales because people in London know that STD clinic facilities are readily available.

Valid conclusions about the equality of STD clinic facilities can only be drawn if the need of the population for those facilities is known. This paper has examined only the provision of the service in relation to crude population. It has not examined the differences in need or demand for STD clinic services. There is little indication of the need of the population because there are no statistics available on the level of untreated STDs in a defined population or on STDs treated by general practitioners and in private practice.

One major factor which may be used as an indicator in the measurement of a population's need for the STD service is the age structure of that population. It is known that the age groups most at risk are those between 16 and 24 years. For instance, for the year ending June 1977 the incidence of new cases of gonorrhoea per 100000 population was 421 $\cdot 49$ for the group aged $16-19$ years and $631 \cdot 15$ for the group aged $20-24$ years. For those over 25 years old, it was only $91 \cdot 35 .^{10}$ Census data for 1971 show that the proportion of the population aged 20-24 is slightly larger in Greater London $(8 \cdot 8 \%)$ than in other counties of England and Wales and still larger in the "conurbation centre" $(11 \cdot 8 \%)$. Thus differences in the age structure of populations could be influential in determining the adequacy of STD clinic provision in relation to those populations.

Within the RHAs internal patterns of distribution of clinics and clinic weekly hours are quite different and these patterns have implications for the STD clinic service provided for the population of that region. Accessibility of an STD clinic to the patient is limited by two major factors; firstly, the geographical distance and travelling time from his home or place of work to a clinic and, secondly, the number of hours of service and the convenience of clinic opening times. Different patterns of distribution of facilities in regional health authorities mean that the accessibility of clinics is different in each region.

For many people not living in conurbations, where access to a clinic is generally easier, the choice lies between travelling much further to a clinic open fulltime and waiting for up to a week to go to a clinic closer to work or home. Other alternatives are either to go to a general practitioner, who does not have laboratory facilities, or, if all of these alternatives are considered unacceptable, to do nothing. Limited accessibility of clinics can only cause delay in treatment, which results potentially in the spread of disease.

The conclusions reached in this paper are based only on comparative relationships between clinic hours of service and catchment population and therefore their use for planning purposes is limited. However, these conclusions do indicate that special descriptive studies would be most valuable for the future planning of the service and allocation of resources.

This study was supported as part of a research contract with the Medical Research Council.

\section{References}

1. Adler MW, Belsey EM, O'Connor BH, Catterall RD, Miller DL. Facilities and diagnostic criteria in sexually transmitted disease clinics in England and Wales. Br J Vener Dis 1978;54: 2-9. 
2. Adler MW. Diagnostic, treatment and reporting criteria for gonorrhoea in sexually transmitted disease clinics in England and Wales. 1 Diagnosis. Br J Vener Dis 1978;54:10-4.

3. Adler MW. Diagnostic, treatment and reporting criteria for gonorrhoea in sexually transmitted disease clinics in England and Wales. 2 Treatment and reporting criteria. Br J Vener Dis 1978;54: 15-23.

4. Belsey EM, Adler MW. Current approaches to the diagnosis of herpes genitalis. Br J Vener Dis 1978; 54:115-20.

5. Adler MW. Diagnostic, treatment, and reporting criteria for non-specific genital infection in sexually transmitted disease clinics in England and Wales. 1 Diagnosis. Br J Vener Dis 1978; 54:422-7.

6. Adler MW. Diagnostic, treatment, and reporting criteria for non-specific genital infection in sexually transmitted disease clinics in England and Wales. 2 Treatment and reporting criteria. Br J Vener Dis 1978; 54:428-32.
7. O'Connor BH, Adler MW. Current approaches to the diagnosis, treatment, and reporting of trichomoniasis and candidosis. Br J Vener Dis 1979;55:52-7.

8. Department of Health and Social Security. Sexually Trans mitted Diseases Clinics. London: Department of Health and Social Security, 1976.

9. Census 1971. England and Wales. Workplace and Transport to Work Tables. Parts 1 and 2 (10\% sample). London: HMSO, 1971.

10. Department of Health and Social Security. On the State of the Public Health for the Year 1977. London: HMSO, 1977. 